\title{
PENGARUH COMPUTER GAME TERHADAP RENTANG SENDI PHALANG PASIEN STROKE DI RS ADI HUSADA SURABAYA 2016
}

\author{
Rina Budi Kristiani \\ Akademi Keperawatan Adi Husada Surabaya \\ rinabudikristiani.rb@gmail.com
}

\begin{abstract}
ABSTRAK
Pasien yang menderita stroke secara mendadak akan mengalami kelemahan ekstremitas, gangguan ini dapat mengganggu kegiatan hidup sehari-hari, tindakan yang dapat dilakukan perawat adalah melakukan range of motion yang menyenangkan dengan menggunakan computer game. Tujuan dari penelitian ini adalah diketahuinya pengaruh computer game terhadap rentang sendi phalang pasien stroke di RS Adi Husada Surabaya. Metode penelitian adalah kuasi eksperimental dengan pre dan postt test di RS Adi Husada Surabaya selama April - Juli 2016 berjumlah 44 responden. Pengambilan sampel dilakukan dengan cara purposive sampling, responden kelompok intervensi (menggunakan computer game) berjumlah 22 responden $(50 \%)$ dan responden kelompok kontrol (menggunakan terapi standar) berjumlah $22(50 \%)$. Jenis kelamin laki-laki 65,9\%, kelompok umur dewasa dengan rentang usia 21-60 tahun sebanyak 56,8\%, serangan stroke sekali sebanyak 79,5\% dan tidak ada dukungan keluarga sebesar $52,3 \%$. Hasil uji beda peningkatan rentang sendi sebelum dan sesudah intervensi pada kelompok intervensi $\left(18.19^{\circ}\right)$ dan kelompok kontrol $\left(3,13^{\circ}\right)$, statistik berbeda signifikan ( $t$-independent test $\mathrm{p}_{\text {value }}=0.021$ ). Hasil Uji perbedaan rentang sendi pada kelompok intervensi sebelum intervensi $\left(43,02^{\circ}\right)$ dan sesudah intervensi $\left(61,21^{\circ}\right)$ statistik berbeda signifikan (t-paired test $\left.\mathrm{p}_{\text {value }}=0,004\right)$. Hasil uji regresi linier berganda untuk melihat pengaruh secara simultan adalah dukungan keluarga dengan $\mathrm{p}_{\text {value }}=0,009(<0,05)$ dan computer game $\mathrm{p}_{\text {value }}=0,000(<0,05)$ berarti ada pengaruh computer game dan dukungan keluarga terhadap rentang sendi phalang pasien stroke. Dari penelitian ini telah dibuat juga persamaan regresi dan dapat disimulasikan untuk visualisasi peran berbagai variabel. Disarankan bagi pelayanan keperawatan khususnya RS Adi Husada Surabaya, untuk menggunakan computer game sebagai sarana dalam membantu melakukan latihan rentang gerak sendi phalang pada pasien stroke yang mengalami kelemahan rentang sendi phalang.
\end{abstract}

Kata Kunci : Stroke, Rentang Sendi Phalang Menurun, Computer Game, Rentang Sendi Meningkat

\section{ABSTRACT}

Patients suffering from a sudden stroke will experience limb weakness, this disorder can interfere with daily living activities, actions that can be performed by nurses are doing range of motion using a computer games that is fun. The purpose of this research is knowing the influence of computer games on phalang joint range of stroke patients in Adi Husada Hospital Surabaya. The research method was quasi experimental with pre and post test design in Adi Husada Hospital Surabaya during April-July, 2016 with a number of 44 respondents. Sampling was done by purposive sampling, respondents in the intervention group (using a computer game) amounted to 22 respondents (50\%) and respondents in the control group (standard therapy) was $22(50 \%)$. Distribution characteristics for the majority of respondents, the male sex of 65,9\%, adult age group 21-60 years 56,8\%, Frequency of stroke in a one time group is $79,5 \%$ and the group of no family support amounted to 52,3\%. Difference test results on improving joint range before and after intervention in the intervention group $\left(18,19^{\circ}\right)$ and in the control groups $\left(3.13^{\circ}\right)$, statistically significantly different ( $t$-independent test pvalue $\left.=0,021\right)$. Difference test results on improving of joints in the intervention group before the intervention $\left(43,02^{\circ}\right)$ and after intervention $\left(61,21^{\circ}\right)$ statistically significant different (paired t-test pvalue $=0,004$ ). The results of multiple regression analysis to see the effect of simultaneously is family support pvalue $=$ $0,009(>0,05)$ and computer game pvalue $=0,000(>0,05)$ means that there is an influence of computer games and family support for the joint range phalanx stroke patients. This research has been made the regression equation and perform simulated for the visualization of the role of different variables. It is recommended for nursing services especially in Adi Husada Hospital Surabaya, to use computer games as a means to help perform range of motion exercises phalanx in stroke patients who experienced weakness phalanx joint range.

Keywords: Stroke, Range Joints Phalanx Reduction, Computer Game, Increase Joint Range 


\section{PENDAHULUAN}

Penurunan fungsi gerak pada tangan sering terjadi setelah stroke, hal ini didukung oleh Rand (2015) bahwa kelemahan ekstremitas atas paling umum terjadi pada pasien post stroke dan sebagian besar pasien mengalami gangguan fungsi pada tangan. Sabini (2013) menyatakan bahwa hemiparese adalah gangguan gerak yang sering dialami pasien setelah stroke dan sering mengakibatkan gangguan fungsi pada tangan. Selain itu menurut Chen (2015) menunjukkan penurunan anggota gerak atas merupakan salah satu tanda dari stroke. Menurut Stroke Association (2013) menyatakan bahwa stroke dapat terjadi pada dewasa muda yaitu sebanyak $25 \%$, antara $40 \%$ $50 \%$ stroke pada dewasa muda disebabkan oleh perdarahan. Kejadian stroke akan meningkat dengan bertambahnya usia dan akan meningkat dua kali lipat pada usia diatas 55 tahun dan dua pertiga kejadian stroke di atas usia 65 tahun.

Pasien stroke yang menjalani rawat inap di RS Adi Husada Surabaya sebanyak 642 pasien pada tahun 2014. Pasien stroke yang mengalami gangguan rentang gerak sendi ekstremitas atas pada tahun 2016 sebanyak 39 pasien dalam 1 bulan. Pasien yang sedang menjalani rawat inap di RS Adi Husada Surabaya mendapatkan latihan rentang gerak sendi oleh tenaga fisioterapi tetapi tidak semua pasien melanjutkan latihan secara mandiri.

Untuk mengurangi tingkat ketergantungan dan mencegah kecacatan yang dialami pasien, perawat perlu melakukan rehabilitasi dini terhadap pasien post stroke dengan melakukan latihan range of motion (ROM). ROM adalah rentang gerak yaitu pergerakan sendi terjauh secara lengkap yang mampu dilakukan secara normal. ROM dapat dilakukan dengan melakukan latihan rentang gerak aktif, aktif dengan bantuan, atau pasif. Latihan tersebut harus dilakukan secara teratur. Latihan aktif dan pasif meningkatkan mobilitas sendi dan meningkatkan sirkulasi ke bagian yang sakit. Latihan aktif meningkatkan fungsi jantung dan pernapasan. Latihan harus memperhatikan kondisi fisik pasien. ${ }^{12}$

Menurut Perry (2011) dan Chen (2015) penggunaan computer game dapat meningkatkan motivasi dan partisipasi pasien untuk melakukan latihan ROM secara rutin dan mengurangi kebosanan karena melakukan kegiatan monoton, dengan pelaksanaan ROM yang terjadual akan membantu meningkatkan fungsi ekstremitas. Perawat bersama dengan pasien dan keluarga memodifikasi media yang dapat digunakan pasien untuk melakukan latihan ROM secara mandiri dan menyenangkan yaitu computer game. Bila hal ini dapat dilakukan proses rehabilitasi pada pasien yang mengalami gangguan rentang gerak sendi akan segera teratasi dan pasien dapat melakukan aktivitas hidup sehari-hari secara mandiri.

Tujuan dari penelitian ini adalah mengidentifikasi pengaruh computer game terhadap rentang sendi Phalang pasien stroke.

\section{METODE}

Penelitian ini menggunakan jenis penelitian quasi eksperimennon equivalent prepost testwith control group di RS Adi Husada Surabaya selama April - Juli 2016 berjumlah 44 responden. Pengambilan sampel dilakukan dengan cara purposive sampling, dibagi menjadi responden kelompok intervensi (computer game) berjumlah 22 responden $(50 \%)$ dan responden kelompok kontrol (terapi standar) berjumlah 22 (50\%). Pada awal penelitian dilakukan pengukuran rentang sendi phalang pada kedua kelompok. Selanjutnya kelompok intervensi dilakukan computer game dengan durasi 30 menit selama 5 hari/minggu selama 4 minggu, dan pada akhir minggu ke 4 dilakukan pengukuran rentang sendi phalang kembali pada kedua kelompok. Analisa data bivariate menggunakan regresi sederhana, uji independent $t$ test, dan paired $t$ test. Analisa Multivariat menggunakan analisa regresi linear berganda.

\section{HASIL}

\section{Data Umum}

Tabel 1. Karakteristik Responden

\begin{tabular}{llcc}
\hline No. & Karakteristik & $\mathrm{n}$ & $\%$ \\
\hline 1 & Jenis kelamin & & \\
\hline & Laki-laki & 29 & 65,9 \\
\cline { 2 - 4 } & Perempuan & 15 & 34,1 \\
\hline 2 & Umur & & \\
\cline { 2 - 4 } & 21-60 th (dewasa) & 25 & 56,8 \\
\cline { 2 - 4 } & >60 th (usila) & 19 & 43,2 \\
\hline 3 & Frekuensi serangan stroke & \\
\cline { 2 - 4 } & Sekali & 35 & 79,5 \\
\cline { 2 - 4 } & Lebih dari sekali & 9 & 20,5 \\
\hline 4 & Dukungan keluarga & & \\
\cline { 2 - 4 } & Ada & 21 & 44,7 \\
\cline { 2 - 4 } & Tidak ada & 23 & 52,3 \\
\hline
\end{tabular}

Karakteristik responden berdasarkan jenis kelamin yang berpartisipasi dalam penelitian ini menunjukkan bahwa jenis kelamin yang terbanyak adalah laki-laki 
sebanyak 29 orang $(65,9 \%)$. Hal ini sesuai dengan Lewis (2011) menyatakan bahwa stroke lebih banyak terjadi pada laki-laki dibandingkan perempuan.Karakteristik responden berdasarkan umur yang berpartisipasi dalam penelitian ini menunjukkan bahwa kelompok umur terbanyak yang mengalami stroke adalah kelompok umur dewasa sebanyak 25 orang $(56,8 \%)$. Karakteristik responden berdasarkan serangan stroke yang berpartisipasi dalam penelitian ini yang terbanyak adalah serangan stroke sekali sebanyak 35 orang (79,5\%). Karakteristik responden berdasarkan dukungan keluarga yang berpartisipasi dalam penelitian ini yang terbanyak adalah responden yang tidak ada dukungan keluarga sebanyak 23 orang $(52,3 \%)$.

\section{Data Khusus}

Hasil penelitian menunjukkan perbedaan rentang sendi phalang antara kelompok intervensi dan kelompok kontrol sesudah intervensi dengan $\mathrm{P}_{\text {value }} 0,021(\mathrm{p}<0,05)$. Hal ini menunjukkan ada perbedaan rentang sendi phalang setelah intervensi antara kelompok intervensi dan kelompok kontrol.

Hasil penelitian didapatkan selisih rentang sendi phalang sebelum dan sesudah intervensi sebesar $18,19^{\circ}$ dengan $\mathrm{p}_{\text {value }} 0,004$ maka dapat disimpulkan secara statistik ada perbedaan rentang sendi phalang sebelum dan sesudah dilakukan intervensi computer game.

Berdasarkan hasil penelitian computer game menunjukkan pengaruh yang signifikan dengan $\mathrm{p}_{\text {value }} 0,000$. Sedangkan variabel umur, jenis kelamin, serangan stroke dan dukungan keluarga tidak mempengaruhi rentang sendi phalang pasien stroke.

Hasil penelitian ini secara parsial menunjukkan ada pengaruh computer game terhadap rentang sendi phalang dengan nilai signifikasi $0,000(\mathrm{p}<0,05)$.

Umur, jenis kelamin dan serangan stroke tidak mempengaruhi rentang sendi phalang ditunjukkan dengan nilai signifikasi $>0,05$. Hal ini didukung oleh Rothsein (1985) yang menyatakan bahwa umur tidak bisa dianggap sebagai faktor pembatas dalam rehabilitasi pasien stroke. Dukungan keluarga mempengaruhi rentang sendi phalang dengan nilai pvalue $0,022<0,005$.

Persamaan regresi dan dapat disimulasikan untuk visualisasi peran berbagai variabel yaitu: $\mathrm{Y}=-0,647+0,276 *$ dukungan keluarga $+0,504 *$ computer game $+0,768 * \mathrm{RS}$ pre intervensi. Adapun contoh dari persamaan ini adalah bila nilai rentang sendi pre $50^{\circ}$, mendapat dukungan keluarga dan bermain tablet komputer selama 20-30 menit akan didapatkan nilai post rentang sendi rata-rata sebesar $89,5^{\circ}$ dengan peningkatan terendah $83,7^{\circ}$ dan tertinggi $95,5^{\circ}$.

\section{PEMBAHASAN}

Berdasarkan hasil penelitian dimana pasien stroke yang mengalami keterbatasan motorik setelah diberikan latihan computer game terhadap sendi phalang menunjukkan perbedaan signifikan pada kelompok intervensi. Hasil tersebut diatas sesuai dengan penelitian yang dilakukan Carabeo (2014) yang menyatakan setelah dua minggu menjalani latihan dengan menggunakan computer game, gerakan tangan pasien menunjukkan perbaikan. Selain itu menurut Perry (2011) dan Chen (2015) menyatakan bahwa computer game dapat meningkatkan motivasi dan partisipasi pasien untuk melakukan latihan rentang ROM secara rutin dan mengurangi kebosanan, sehingga dapat meningkatkan fungsi ekstremitas. ${ }^{7}$ Hal ini menunjukkan bahwa permainan komputer dapat digunakan sebagai sarana terapi untuk membantu untuk pasien stroke dengan kelemahan tangan. Latihan dengan permainan komputer secara rutin akan meningkatkan kemampuan rentang gerak sendi. Latihan secara mandiri akan meningkatkan self care agency untuk memenuhi tuntutan kebutuhan hidup sehari-hari. Peran dari nursing agency juga menentukan keberhasilan dari pemulihan rentang sendi pasien stroke, tindakan yang dapat dilakukan perawat adalah mendampingi dan memberikan arahan pada pasien saat melakukan latihan rentang gerak dengan menggunakan media alternatif seperti permainan komputer.

Pasien stroke yang mengalami kelemahan ekstremitas atas berusaha memenuhi perawatan dirinya (self care), dengan keterbatasan yang dimiliki tersebut, pasien stroke tidak mampu memenuhi seluruh kebutuhan perawatan dirinya secara mandiri (self-care deficit). Ketidakmampuan penderita dalam melakukan perawatan diri (self - care agent) dalam melakukan aktivitas secara mandiri (self care demand). Disinilah diperlukannya peran perawat dalam memenuhi kebutuhan perawatan bagi pasien stroke yang dapat tergambar dari nursing system Orem, dimana dibutuhkan asuhan keperawatan yang dilakukan perawat untuk menggunakan nursing agency dalam membantu penderita yang mengalami defisit perawatan diri. Dalam teorinya, Orem menekankan bahwa kebutuhan 
self - care dari individu dapat dipenuhi oleh perawat, individu atau oleh keduanya. ${ }^{2}$ Dalam melakukan tindakan keperawatan peneliti mengajarkan kepada pasien atau responden juga keluarga dan orang yang terlibat dalam membantu latihan rentang sendi phalang tentang cara menggunakan computer game untuk membantu melatih perherakan sendi phalang dengan permainan yang dapat diperoleh dengan cara yang mudah dan menyenangkan. Disinilah peran perawat sebagai fasilitator membantu pasien yang mengalami defisit perawatan diri dalam memandirikan baik pasien, keluarga dan orang lain yang ikut merawat sehingga pasien atau keluarga dapat menggunakan dirinya sendiri sebaik mungkin dalam usaha perawatan dirinya.

Berdasarkan hasil penelitian dan studi literatur menunjukkan bahwa umur, jenis kelamin dan serangan stroke tidak mempengaruhi rentang sendi pasien stroke. Terdapat faktor lain yang perlu diteliti yang dapat mempengaruhi rentang sendi pada pada pasien stroke. Faktor lain yang terdapat baik dari dalam maupun dari luar individu dapat mempengaruhi self care agency pasien stroke dalam menghadapi dan menjalani proses pemulihan terhadap keterbatasan rentang sendi phalang. Bila faktor tersebut dapat digunakan secara maksimal, pemulihan rentang sendi phalang pada 3-6 bulan pertama post stroke.

\section{SIMPULAN}

1. Ada perbedaan signifikan rentang sendi phalang pada kelompok intervensi sebelum intervensi $\left(43.02^{\circ}\right)$ dan sesudah intervensi computer game $\left(61.21^{\circ}\right) \mathrm{p}_{\text {value }}=0.004$.

2. Ada pengaruh computer game secara simultan terhadap rentang sendi phalang dengan $\mathrm{p}_{\text {value }}=0.000(<0.05)$ dan dukungan keluarga dengan $\mathrm{p}_{\text {value }}=0.009$. sedangkan umur 0.786, jenis kelamin 0.074 dan serangan stroke 0.423 tidak mempengaruhi rentang sendi phalang ditunjukkan dengan nilai $\mathrm{p}_{\text {value }}>0.05$.

3. Analisis regresi melibatkan variabel yang secara statistik signifikan saja dan rentang sendi pre intervensi dapat dibuat persamaan matematis: $Y$ (rentang sendi post intervensi) $=-0.647+0.276 *$ (dukungan keluarga $)+$ $0.504 *($ computer game $)+0.768 *(\mathrm{RS}$ pre intervensi), untuk simulasi visual peran berbagai variabel.

\section{SARAN}

Computer game sebagai sarana untuk membantu melakukan latihan rentang gerak sendi phalang pada pasien stroke yang mengalami kelemahan rentang sendi phalang.

\section{DAFTAR PUSTAKA}

1. Alankus, G. 2010. Towards Customizable Games for Stroke Rahabilitation. Therapy and Rehabilitation, 2113-2122.

2. Alligood, M. R. 2014. Nursing Theorsts and Their Work, Edition 8. St. Louis Missouri: Mosby, Elsevier.

3. Appelros, P., Stegmayr, B., \& Terent, A. 2009. Sex Differences in Stroke Epidemiology. Journal of The American Heart Association, 9.

4. Billinger, S. A. 2014. Physical Activity and Exercise Recommendations for Stroke Survivors. AHA/ASA Scientific Statement, 1-22.

5. Brass, L. 2002. Stroke. Yale University School of Medicine, 19.

6. Carabeo, C. G., Dalida, C. M., Padilla, E. M., \& Rodrigo, M. T. 2014. Stroke Patient Rehabilitation : A Pilot Study of an Android-Based Game. Simulation \& Gaming, 151-166.

7. Chen, M.-H. 2015. A Controlled Pilot Trial of Two Commercial Video Games for Rehabilitation of Arm Function After Stroke. Clinical Rehabilitation, 674-682.

8. English, B. A., \& Howard, A. M. 2014. Engagement Study of an Integrated Rehabilitation Robotic Tablet-Based Gaming System. Georgia Institute of Technology Atlanta, 6.

9. Fheodoroff, K., Ashford, S., Jacinto, J., Maisonobe, P., Balcaitiene, J., \& TurnerStokes, L. 2015. Factors Influencing Goal Attainment in Patient with PostStroke Upper Limb Spasticity Following Treatment with Botulinum Toxin A in Real-Life Clinical Practice : SubAnalyses from The Upper Limb International Spasticity (ULIS)-II Study. Toxin, 1192-1205.

10. Iosa, M. 2012. Seven Capital Devices for the Future of Stroke Rehabilitation. Stroke Research and Treatment, 10.

11. Laloux, Lemonnier, \& Jamart. 2010. Risk factors and treatment of stroke at the time of recurrence. Acta Neurology, 4.

12. Lillis, T., \& Lynn, L. 2011. Fundamental of Nursing The Art and Science of Nursing Care. Philadelphia: Wolters Kluwer Health.

13. Maeshima, S. 2013. Family Support in Stroke Rehabilitation. International 
Journal of Physical Medicine \& Rehabilitation, 1.

14. McEwen, M., \& Wills, E. M. 2011. Theoretical Basis For Nursing. Philadelphia: Lippincott.

15. Miller, E. L. 2010. Comprehensive Overview of Nursing and Interdisciplinary Rehabilitation Care of The Stroke Patient. AHA Scientific Statement, 2402-2448.

16. Paolucci, S., Bragoni, M., Coiro, P., De Angelis, D., Fusco, F., Morelli, D., Pratesi, L. 2006. Is Sex a Prognostic Factor in Stroke Rahabilitation? A Matched Comparison. American Heart Association, 6.

17. Perry, J. C. 2011. Effective Game Use in Neurorehabilitation: User-Centered Perspectives. Fatronik FoundationTECNALIA, 1-44.

18. Polit, D. F., \& Beck, C. T. 2012. Nursing Research. Philadelphia: Wolters Kluwer Health.
19. Rand, D., Zeilig, G., \& Kinozy, R. 2015. ReHab-let: Touchscreen Tablet for SelfTraining Impaired Dexterity Post Stroke: Study Protocol For a Pilot Randomized Controlled Trial. BioMed Central, 1-7.

20. Rothstein, J. M. 1985. Measurement in Physical Therapy. New York: Churchill Livingstone.

21. Sabini, R. C. 2013. Stroke Survivors Talk While Doing : Development of A Therapeutic Framework for Continued Rehabilitation of Hand Function Post Stroke. Journal of Hand Therapy, 124131.

22. Stroke, A. 2013. Stroke Statistics. Stroke, 1-13.

23. Urimubenshi, \& Rhoda. 2011. Environmental barriers experienced by stroke patients in Musanze district in Rwanda: a descriptive qualitative study. African Health Sciences, 9. 